\title{
Research of dependences of idle losses of transformers TM-400/10 on voltage according to synchronous measurements
}

\author{
Pavel Zvada, Evgenii Zelenskii, Yuri Kononov, Svetlana Kostyukova, and Evgeny Dernin \\ FSAEI HE "North-Caucasus Federal University", Stavropol, Russia
}

\begin{abstract}
The article presents the dependences of the active and reactive components of the losses of the idle transformer on the mains voltage. It is proposed to evaluate the no-load losses using an alternative method for identifying the parameters of the transformer based on high-precision synchronous measurements. Within the framework of a pilot project on a real feeder, using the technology of synchronous measurements, the dependences of no-load losses on voltage were identified. For transformers installed in a distribution network, the dependence of losses on voltage is not quadratic, but has a higher order. It was determined that the dependence of losses in a transformer on voltage for active power has a power of 6.35, and for reactive power has a power of 7.4.
\end{abstract}

\section{Introduction}

When solving many practical problems in distribution networks (calculations and optimization of operation and places of network sectioning, power consumption, diagnostics of transformer faults), increased accuracy of transformer modeling is required, including the dependence of no-load losses (NL) on voltage. The existing practice assumes modeling of NL in constant active and reactive conductivity [1-4], which corresponds to the quadratic dependence of the losses of both active and reactive power from the module. However, it is known from the theory of calculation and design of transformers that in reality these are associated with the use of a transformer and are of a more complex nature [5]. For, in Figures 1 and 2, examples of the dependence of the specific power and magnetizing power for cold-rolled steel grade 3404 at various inductions.

It can be seen from the above figures that, depending on the considered working range of electromagnetic induction, in which the transformer operates, the exponent can vary significantly (from about 1.7 to 40). The quadratic dependence can be traced only in a narrow range of 1.5-1.7 T. Despite the fact that in most cases transformers are trying to design so that its operating is in this range, the function of the dependence of open-circuit losses on electromagnetic induction, and, consequently, voltage, for a specific transformer requires clarification.

The actual dependences of NL on voltage can be determined in laboratory conditions or in field tests associated with disconnecting the transformer from the network. An alternative to this solution can be the identification of transformer parameters based on high-precision synchronous measurements [6]. 


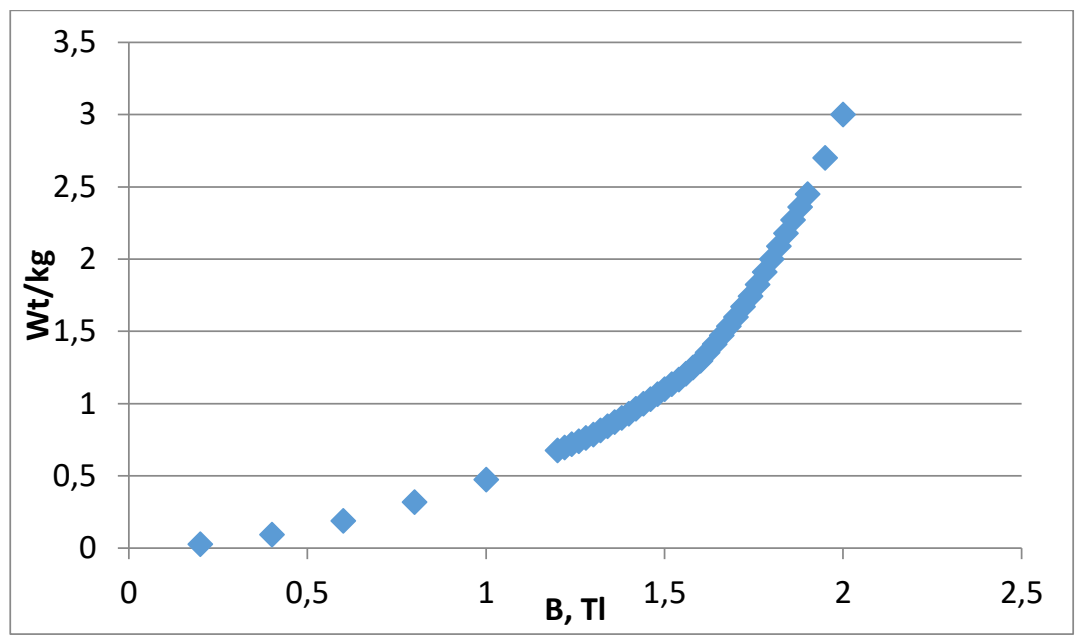

Fig. 1. Specific losses in steel for cold-rolled steel of grade 3404 at various inductions

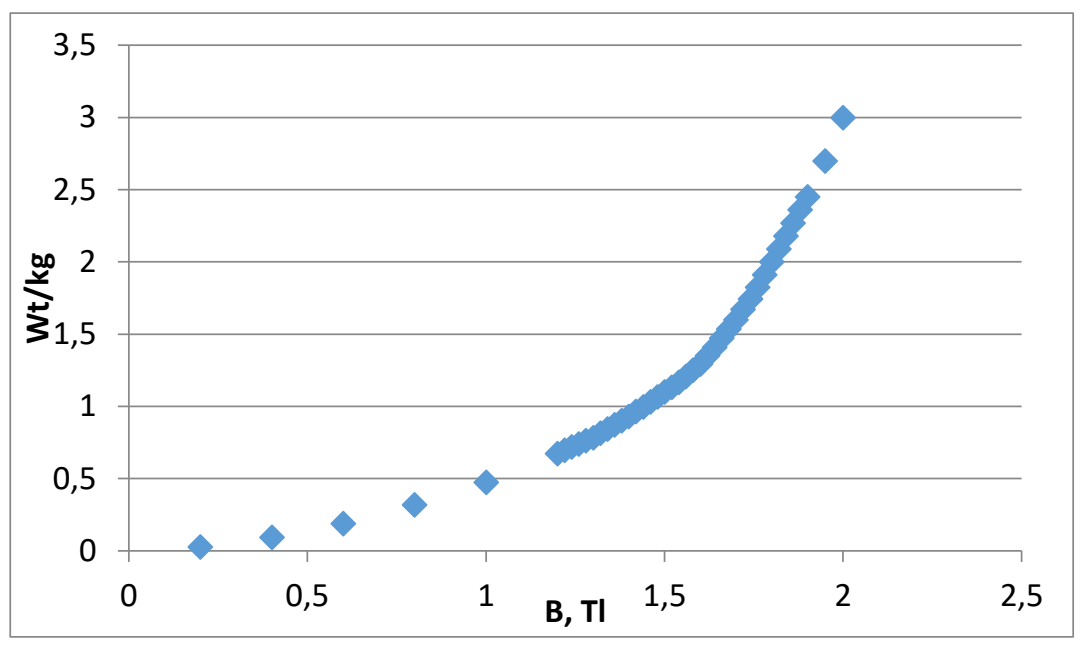

Fig. 2. Total specific magnetizing power in steel q for cold-rolled steel of grade 3404 at various inductions

However, the implementation of synchronous measurement technologies in distribution networks requires the solution of many technical problems, including the development of inexpensive measuring systems with the function of synchronous measurements $[7,8]$.

With the support of the Ministry of Science and Education, within the framework of applied research work on the topic "development and research of an intelligent system for automated metering of electricity in $0.4-10 \mathrm{kV}$ distribution networks with the function of localizing commercial and technical losses of electricity", together with JSC Energomera, experimental samples were developed three-phase electronic measuring devices (IED). The developed IEDs make it possible to perform synchronized measurements of oscillograms of currents and voltages with a given frequency (640 samples with a sampling rate of $16 \mathrm{kHz}$, which corresponds to two periods of the network).

The measuring part of the IED is based on the Texas Instruments ADS131E08 microcircuit, which contains a 24-bit sigma-delta ADC. To synchronize the measurements, a GPS / GLONASS signal receiving module NAVEL and an AD9548 phase-locked loop from Analog Devices are used. 
The technical characteristics of the IED are presented in Table 1.

Table 1. Characteristics of three-phase IEDs.

\begin{tabular}{|c|c|c|}
\hline Parameter & $\begin{array}{c}\text { Unit of } \\
\text { measurement }\end{array}$ & $\begin{array}{c}\text { Parameter } \\
\text { value }\end{array}$ \\
\hline $\begin{array}{c}\text { Phase voltage measurement } \\
\text { accuracy }\end{array}$ & $\delta \mathrm{u}, \%$ & \pm 0.1 \\
\hline $\begin{array}{c}\text { Phase current measurement } \\
\text { accuracy }\end{array}$ & $\delta \mathrm{i}, \%$ & \pm 0.1 \\
\hline Power measurement accuracy & $\delta, \%$ & \pm 0.5 \\
\hline ADC type & - & $\Delta \Sigma$ \\
\hline ADC bit depth & $\mathrm{Bit}$ & 24 \\
\hline Oscilloscope duration & $\mathrm{sec}$. & 0.04 \\
\hline Sampling frequency & $\mathrm{kHz}$ & 16 \\
\hline Operating temperature range & ${ }^{\circ} \mathrm{C}$ & -40 to +60 \\
\hline
\end{tabular}

\section{Pilot project}

Within the framework of applied research work, a pilot project was implemented on an operating $10 \mathrm{kV}$ feeder belonging to the municipal grids of the city of Mikhailovsk, Stavropol Territory. The single-line diagram of the feeder is shown in Figure 3. In normal mode, the feeder feeds 12 single-transformer substations $10.0 / 0.4 \mathrm{kV}$ [8].

All transformer substations, except for transformer substation-12/230, have transformers with a Y / Yn-12 winding connection diagram. At substation 12/230, the transformer has a $\Delta / \mathrm{YH}_{\mathrm{H}} 11$ scheme. The feeder receives power from the $10 \mathrm{kV}$ buses of the $35 / 10 \mathrm{kV}$ substation. At the $10 / 0.4 \mathrm{kV}$ transformer substation, the current circuits of the IED were connected to the stationary TT IEK "TTI-A", the characteristics of which are presented in Table 2.

Table 2. Technical characteristics of current transformers.

\begin{tabular}{|c|c|c|c|}
\hline Rated voltage, $\mathbf{k V}$ & $\begin{array}{c}\text { Rated secondary } \\
\text { current, } \mathbf{A}\end{array}$ & $\begin{array}{c}\text { Rated secondary } \\
\text { load, VA }\end{array}$ & Accuracy class \\
\hline 0.66 & 5 & 5 & 0.5 \\
\hline
\end{tabular}

In the power center, the IED was connected to TA and TV, the characteristics of which are shown in Table 3. 


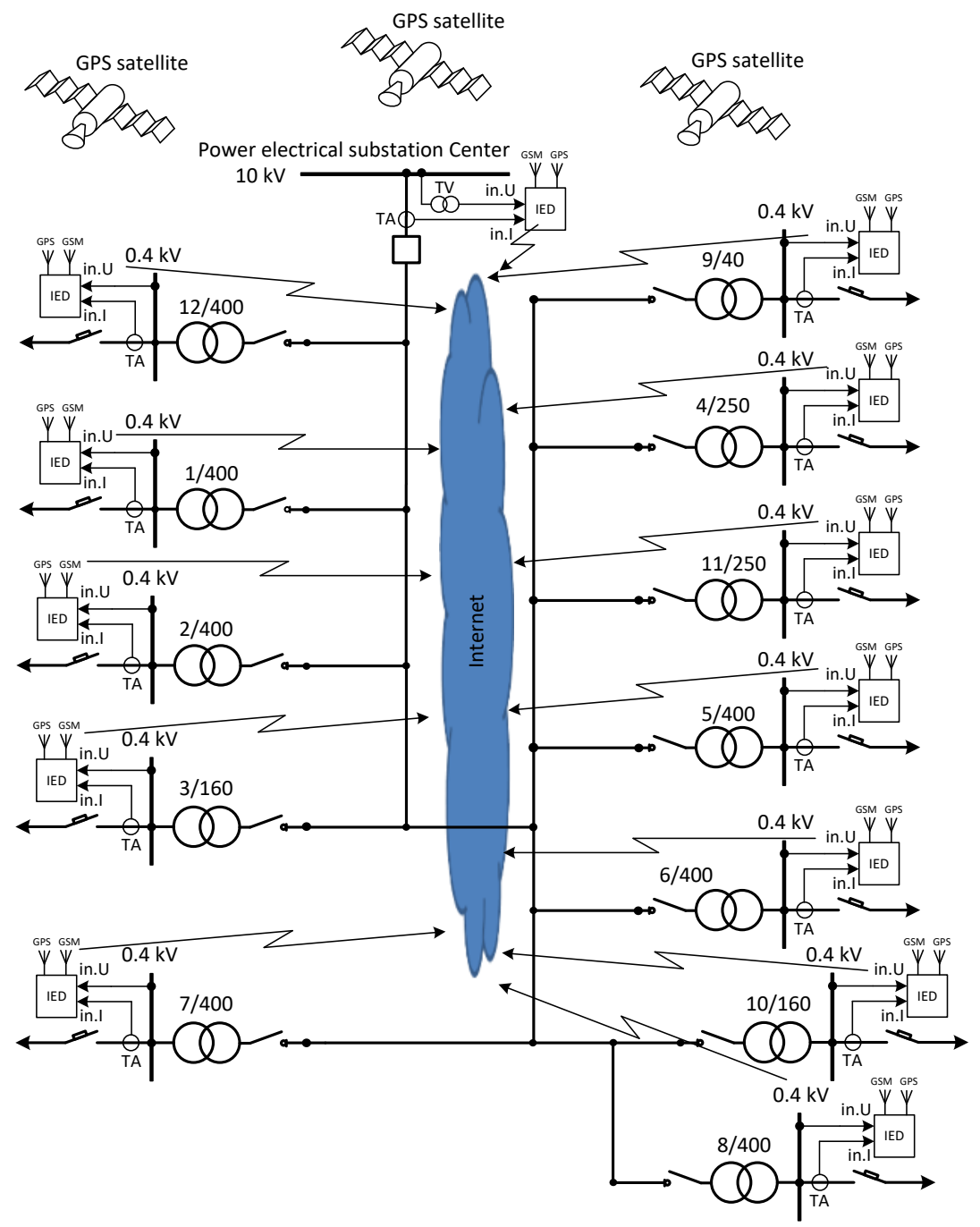

Fig. 3. Single line feeder diagram

Table 3. Technical characteristics of current transformers.

\begin{tabular}{|c|c|c|}
\hline Instrument transformer type & TA & TV \\
\hline Rated voltage, $\mathrm{kV}$ & 10 & 10 \\
\hline $\begin{array}{c}\text { Rated primary current, A / } \\
\text { primary voltage V }\end{array}$ & 200 & $10000 / \sqrt{ } 3$ \\
\hline $\begin{array}{c}\text { Rated secondary current, A / } \\
\text { secondary voltage }\end{array}$ & 5 & $100 / \sqrt{ } 3$ \\
\hline Rated secondary load, VA & 5 & 400 \\
\hline Accuracy class & 0.2 & 0.2 \\
\hline
\end{tabular}


The measured samples of phase voltages and currents at an interval of $40 \mathrm{~ms}$ according to a given schedule (with a periodicity of 5 or 10 minutes) were transmitted via GSM modems to the data collection server.

During the implementation of the pilot project, it was revealed that the use of the classical quadratic dependence of no-load losses on the voltage module introduces significant errors in the operation of the developed system for localizing commercial and technical losses of electricity.

\section{Dependence of no-load losses on voltage}

To study the dependence of no-load losses on voltage, the post-emergency mode of the feeder was used, in which 10 out of 12 substations are supplied with energy from the backup power center. Emergency sectioning of the feeder is carried out at transformer substation $2 / 230$. In this mode, the considered feeder consists of only two transformer substations $1 / 230$ and $2 / 230$, while the line outgoing from $1 / 230$ to $2 / 230$ is energized in idle mode. The line consists of two parallel sections made with AABL- $3 \times 240$ cable 200 meters long. Table 4 shows the time intervals during which, according to information from the operational dispatch service, the feeder worked in the above mode.

Table 4. Operating time intervals of the F-230 feeder, during which only transformer substations $12 / 230$ and $1 / 230$ were operated from $10 \mathrm{kV}$ buses of the «Airport» substation.

\begin{tabular}{|c|c|c|}
\hline date & Start time & End time \\
\hline 01.03 .2016 & $6: 00$ & $9: 30$ \\
\hline 01.03 .2016 & $14: 00$ & $24: 00$ \\
\hline 02.03 .2016 & $0: 00$ & $4: 30$ \\
\hline 11.04 .2016 & $6: 00$ & $24: 00$ \\
\hline 12.04 .2016 & $0: 00$ & $5: 00$ \\
\hline 22.07 .2016 & $8: 00$ & $12: 30$ \\
\hline 28.07 .2016 & $9: 00$ & $15: 00$ \\
\hline 01.08 .2016 & $0: 30$ & $23: 30$ \\
\hline 30.09 .2016 & $6: 00$ & $24: 00$ \\
\hline 12.10 .2016 & $9: 20$ & $14: 50$ \\
\hline
\end{tabular}

For these time intervals, an analysis was carried out of the oscillograms of currents and voltages obtained by the automated system of control and metering of energy resources (ASCME) from the above two substations and the power center. The signals of currents and voltages were expanded in a Fourier series; only the first harmonic was isolated for further analysis. For it, for each phase, the powers of the active and reactive load at the substations are determined. From the set of measurements of modes from the time intervals presented in Table 1, those were selected in which the load power at each transformer substation did not exceed 5\% of the nominal power. In such modes, the load losses of the transformers are extremely small compared to the no-load losses and can be neglected. For these modes, the losses of active and reactive power were determined as the algebraic sum of the powers of the loads in each phase and the power of the power center. Based on the results 
of calculations, the dependence of no-load losses of active and reactive power on the positivesequence voltage in the power center was built (Figure 4).

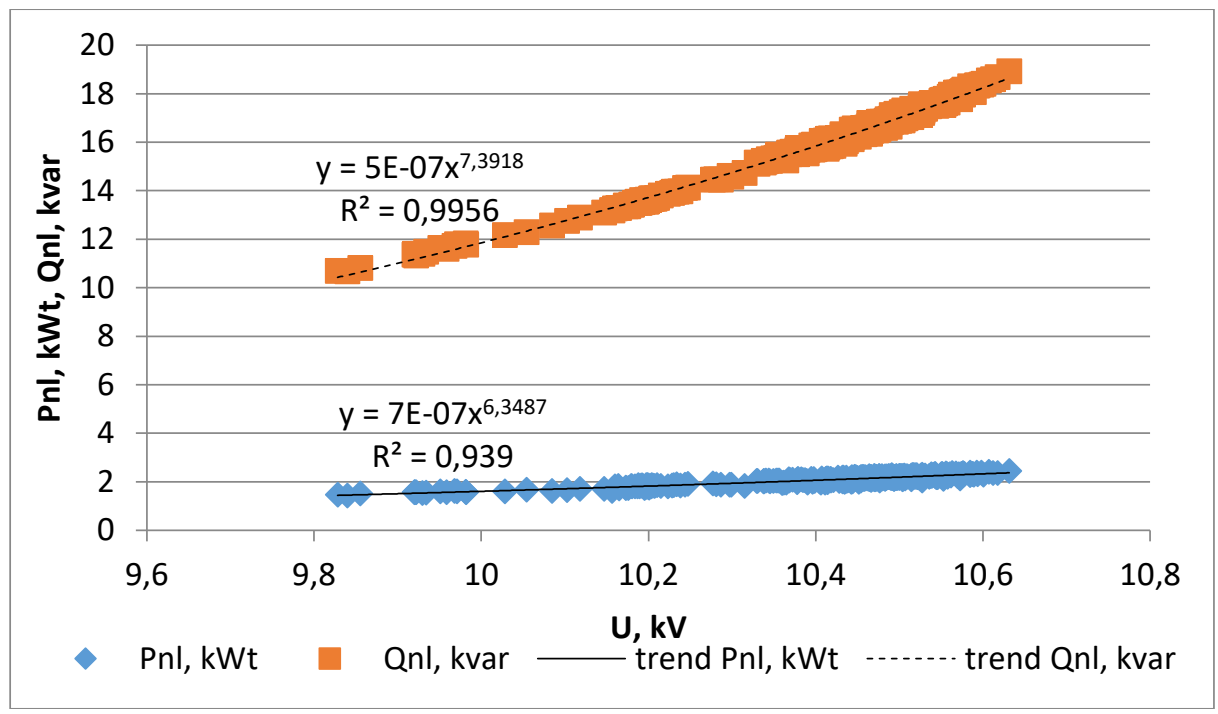

Fig. 4. Single line feeder diagram

As can be seen from the figure, the dependence of the losses XX is fairly well approximated by a power function (the correlation coefficient is more than 0.93), however, the dependence has not a quadratic, but a higher order (for active power, the power is 6.35 , for reactive power, 7.4). Figures 5 and 6 show a comparison of the theoretical (quadratic) dependence of no-load losses for the two considered transformers and the dependence obtained in practice.

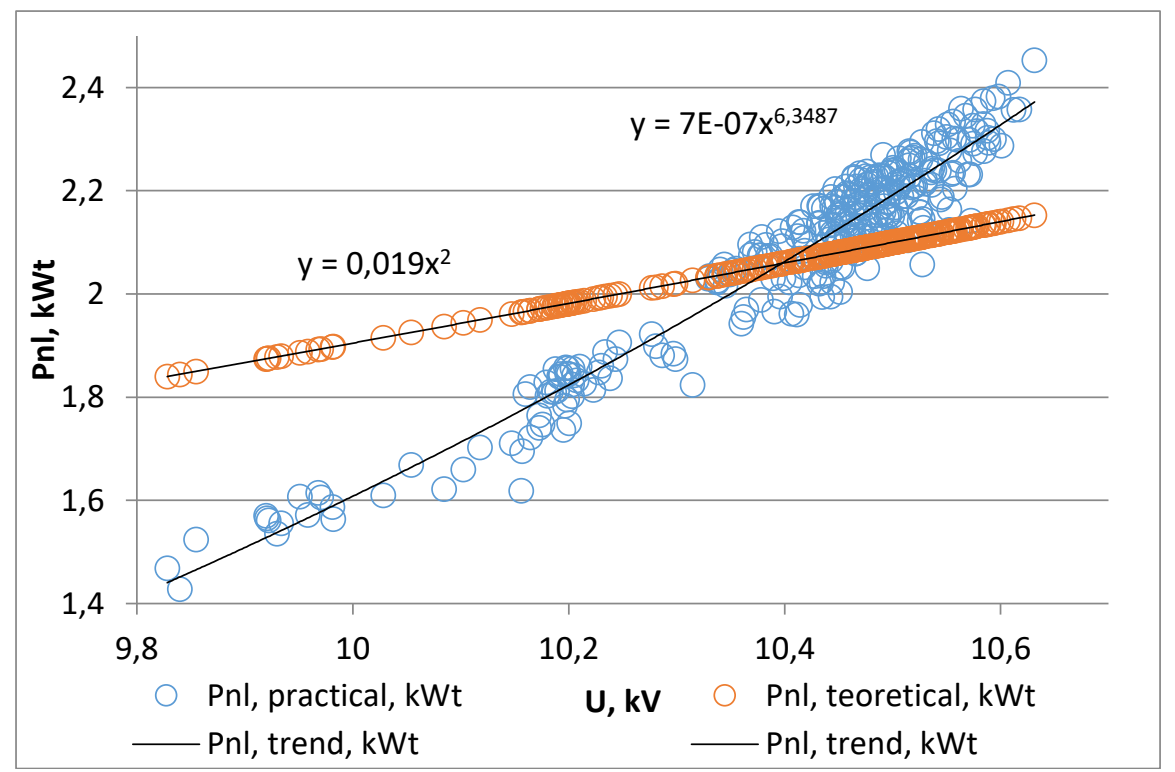

Fig. 5. Comparison of the theoretical (quadratic) dependence of active no-load losses for the two considered transformers and the dependence obtained in practice. 


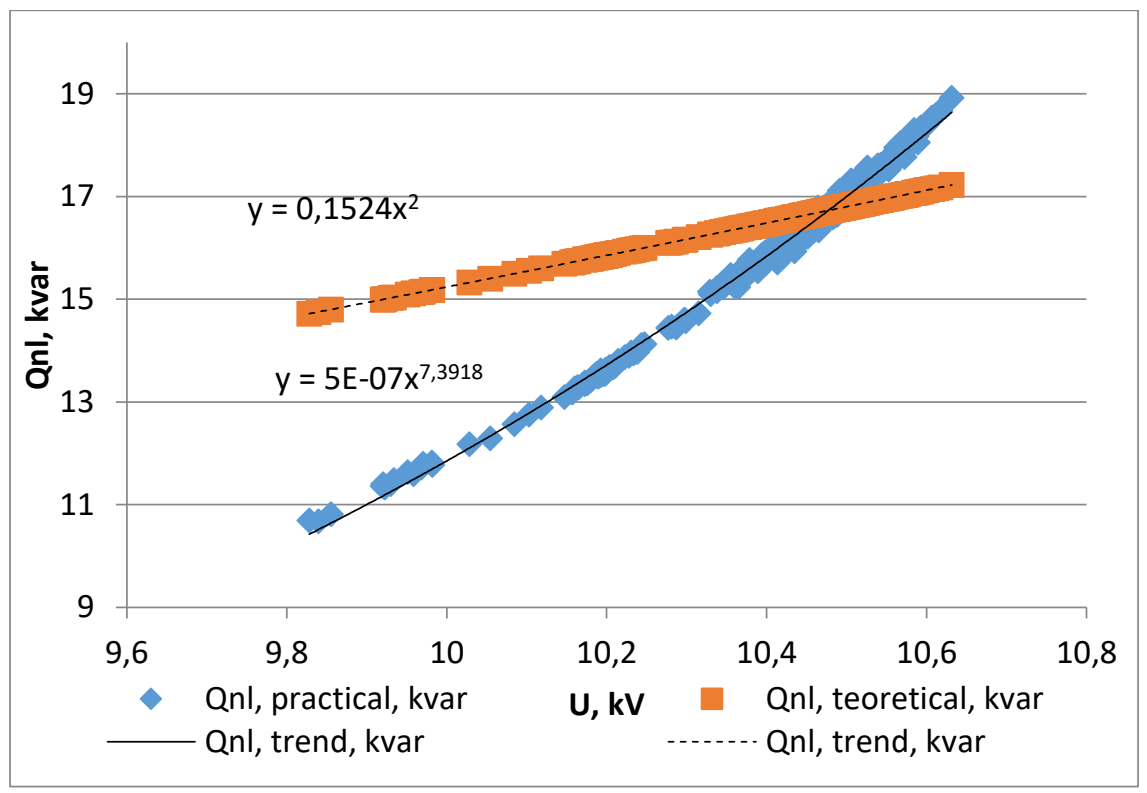

Fig. 6. Comparison of the theoretical (quadratic) dependence of the no-load reactive losses for the two transformers under consideration and the dependence obtained in practice.

As can be seen from the presented data, depending on the mains voltage, the error in modeling noload losses by a quadratic dependence can reach up to $25 \%$ of real losses. Based on this, it is proposed to model the no-load losses of transformers with a polynomial of the second degree (Figure 7).

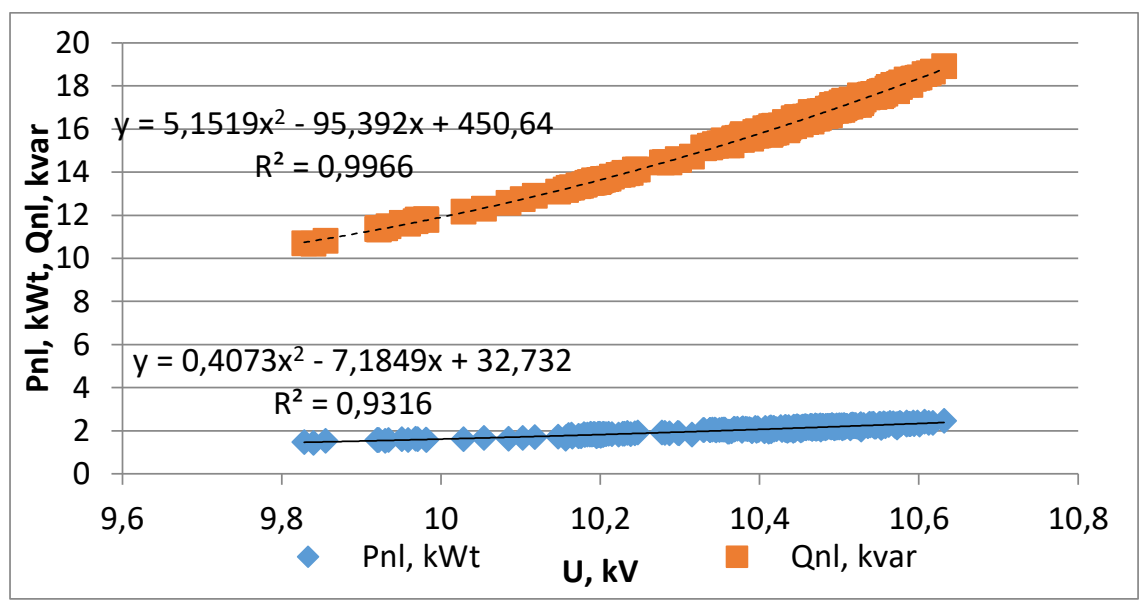

Fig. 7. Modeling no-load losses of transformers by polynomials of the second degree.

\section{Conclusion}

The proposed approach made it possible to improve the accuracy of the developed system for the localization of commercial and technical losses of electricity.

Conclusions:

1. The existing method of accounting for no-load losses in transformers in the form of constant conductivity requires clarification. 
2. Real dependences of no-load losses on voltage can be determined in laboratory conditions or in field tests associated with disconnecting the transformer from the network. An alternative to this solution can be the identification of transformer parameters based on high-precision synchronous measurements [10 - 14].

3. Within the framework of a pilot project on a real feeder, using the technology of synchronous measurements, the dependences of no-load losses on voltage were revealed. For the transformers under consideration, the dependence has not a quadratic, but a higher order (for active power, the power is 6.35, for reactive power, 7.4).

4. It is proposed to model the no-load losses of transformers by polynomials of the second degree.

\section{References}

1. IEEE Std C57.123 ${ }^{\mathrm{TM}}-2019$ (Revision of IEEE Std C57.123-2010) IEEE Guide for Transformer Loss Measurement

2. Idel'chik V. I. Elektricheskie sistemy i seti: Uchebnik dlya vuzov. (1989)

3. Gerasimenko A.A., Fedin V.T. Peredacha i raspredelenie elektricheskoj seti (2008)

4. Kamran Dawood, Guven Komurgoz, Dr. Fatih Isik Modeling of Distribution Transformer for Analysis of Core Losses of Different Core Materials Using FEM. 2019 8th International Conference on Modeling Simulation and Applied Optimization (ICMSAO)

5. Separation of No-Load Losses for Distribution Transformers Using Experimental Methods:Two Frequencies and Two Temperatures Juan C. Olivares-Galván, Rafael Escarela-Pérez, Pavlos S. Georgilakis, Eduardo CamperoLittlewood, 7th Mediterranean Conference and Exhibition on Power Generation, Transmission, Distribution and Energy Conversion 7-10 November 2010, Agia Napa, Cyprus (Paper No. MED10/169)

6. E. Hajipour, P. Rezaei, M. Vakilian, and M. Ghafouri, Journal of Electromagnetic Analysis and applications, 3 (10), 430-438, (2011)

7. Tihomirov P. M. Raschet transformatorov: Ucheb. posobie dlya vuzov. (1986)

8. Development of methods for operational identification of parameters of three-winding transformers Yu.G. Kononov, S.A. Stepanov. Proceedings of higher educational institutions. Electromechanics. 2014. No. 3. S. 91-93.

9. P. Zvada;Ju. Pitko Analysis of the Use of Synchronization Methods in Intelligent Electronic Devices 2018 International Conference on Industrial Engineering, Applications and Manufacturing (ICIEAM)

10. Kononov Yu.G., Zvada P.A., Gladkiy E.P. Prospects for the use of synchronous measurements in electrical networks. Actual problems of power engineering, electronics and nanotechnology. Materials of the IV-th annual scientific-practical conference of the North Caucasus Federal University. 114-118 (2016)

11. The experimental studies to improve the measurements synchronization accuracy in the $10 \mathrm{kV}$ feeder at zero crossing by calculated compensation of phase shift of voltage Zvada, P., Zelenskii, E., Kononov, Y. 21st IMEKO TC-4 International Symposium on Understanding the World through Electrical and Electronic Measurement, and 19th International Workshop on ADC Modelling and Testing, (2016)

12. Ronglun Zhang, Shuai Wang, Haibao Mu Guanjun Zhang and Song Huang: Onsite Detecting Method for the Loss Characteristic in 110kV Power Transformer 
IEEE International Conference on High Voltage Engineering and Application (ICHVE), pp. 1-4, (2018).

13. Kui Mu, Sixiang Zhao and Yiping Fan. Transformer, 52(11), 65-70, (2015)

14. Arseneau R., Hanique E., IEEE Trans. Instrum. Meas., 54(2), 503-506 (2005) 